Eur. J. Mineral.

2018, 30, 681-694

Published online 3 April 2018

\title{
Heat capacity and entropy behavior of andradite: a multi-sample and -methodological investigation
}

\author{
Charles A. GEIGER ${ }^{1, *}$, Edgar DACHS ${ }^{1}$, NOREEn M. VIELREICHER ${ }^{1}$ and GEOrGe R. ROSSMAN ${ }^{2}$ \\ ${ }^{1}$ Department of Chemistry and Physics of Materials, Division Materials Science and Mineralogy, University of \\ Salzburg, Jakob Haringer Strasse 2a, 5020 Salzburg, Austria \\ *Corresponding author, e-mail: ca.geiger@sbg.ac.at \\ ${ }^{2}$ Division of Geological and Planetary Sciences, California Institute of Technology, Pasadena, \\ CA 91125-2500, USA
}

\begin{abstract}
Andradite, ideal end-member formula $\mathrm{Ca}_{3} \mathrm{Fe}^{3+}{ }_{2} \mathrm{Si}_{3} \mathrm{O}_{12}$, is one of the common rock-forming garnets found in the Earth's crust. There are several outstanding questions regarding andradite's thermodynamic and physical property behavior. Three issues are: i) Could there be differences in the thermodynamic properties, namely heat capacity, $C_{p}$, between synthetic and natural andradite crystals, as observed in the Ca-garnet grossular, $\mathrm{Ca}_{3} \mathrm{Al}_{2} \mathrm{Si}_{3} \mathrm{O}_{12}$ ? ii) What is the thermal nature of the low-temperature magnetic-phasetransition behavior of andradite? and iii) How quantitative are older published calorimetric (i.e., adiabatic and DSC) heat-capacity results? In this work, four natural nearly end-member single crystals and two synthetic polycrystalline andradite samples were carefully characterized by optical microscope examination, X-ray powder diffraction, microprobe analysis, and IR and UV/VIS single-crystal spectroscopy. The IR spectra of the different samples commonly show a main intense $\mathrm{OH}^{-}$stretching band located at $3563 \mathrm{~cm}^{-1}$, but other $\mathrm{OH}^{-}$bands can sometimes be observed as well. Structural $\mathrm{OH}^{-}$concentrations, calculated from the IR spectra, vary from about 0.006 to $0.240 \mathrm{wt} \% \mathrm{H}_{2} \mathrm{O}$. The UV/VIS spectra indicate that there can be slight, but not fully understood, differences in the electronic state between synthetic and natural andradite crystals. The $C_{p}$ behavior was determined by relaxation calorimetry between 2 and $300 \mathrm{~K}$ and by differential scanning calorimetry (DSC) methods between 150/300 and 700/950 K, employing the same andradite samples that were used for the other characterization measurements. The low-temperature $C_{p}$ results show a magnetic phase transition with a Néel temperature of $11.3 \pm 0.2 \mathrm{~K}$, which could be slightly affected by the precise electronic state of Fe ${ }^{2+/ 3+}$ in the crystals. The published adiabatic calorimetry results on andradite do not provide a full and correct thermal description of this magnetic transition. The calorimetric $C_{p}$ measurements give a best estimate for the standard third-law entropy at $298.15 \mathrm{~K}$ for andradite of $S^{\mathrm{o}} \approx 324 \pm 2 \mathrm{~J} / \mathrm{mol} \cdot \mathrm{K} v s$. the value of $316.4 \pm 2.0 \mathrm{~J} / \mathrm{mol} \cdot \mathrm{K}$, as given in an early adiabatic investigation. Both natural and synthetic crystals give similar $S^{\mathrm{o}}$ values within experimental uncertainty of about $1.0 \%$, but one natural andradite, richer in $\mathrm{OH}$, may have a very slightly higher value around $S^{\circ} \approx 326 \mathrm{~J} / \mathrm{mol} \cdot \mathrm{K}$. Low-temperature DSC measurements made below $298 \mathrm{~K}$ agree excellently with those from relaxation calorimetry. The DSC measurements above $298 \mathrm{~K}$ show a similarity in $C_{p}$ behavior among natural and synthetic andradites. A $C_{p}$ polynomial for use above room temperature to approximately $1000 \mathrm{~K}$ was calculated from the data on synthetic andradite giving: $C_{p}(\mathrm{~J} / \mathrm{mol} \cdot \mathrm{K})=599.09( \pm 14)-2709.5( \pm 480) \cdot T^{-0.5}-1.3866( \pm 0.26) \cdot 10^{7} \cdot T^{-2}+1.6052( \pm 0.42) \cdot 10^{9} \cdot T^{-3}$.
\end{abstract}

Key-words: andradite; heat capacity; entropy; thermodynamics; relaxation calorimetry; DSC; IR spectroscopy; UV/VIS spectroscopy; magnetic phase transitions.

\section{Introduction}

Andradite, ideal end-member formula $\mathrm{Ca}_{3} \mathrm{Fe}^{3+}{ }_{2} \mathrm{Si}_{3} \mathrm{O}_{12}$, is one of the common silicate garnets found in Earth's crust. Close to end-member andradite can occur in nature, for example, at the well-known locality of Val Malenco, Italy, where it occurs in serpentinite formed during the metamorphism of ultramafic rocks. There, it is yellowgreen to green in color and the gem variety name for such crystals is known as demantoid. Other andradite occurrences are known and the crystals can deviate to various degrees from strict end-member andradite composition (e.g., Bocchio et al., 2010). Andradite-rich garnet, commonly in solid solution with grossular, can be found in nature. A common occurrence is in contact metamorphic rocks, especially skarns (Huckenholz \& Yoder, 1971). Other types of occurrences have been reported including, for example, low-grade regionally metamorphosed rocks ( $T=300$ to $400{ }^{\circ} \mathrm{C}$ or less) including metabasites and volcanic sandstones (Coombs et al., 1977).

There have been a number of phase-equilibrium studies made to determine the stability of andradite under different $P-T-f_{\mathrm{O} 2}$ conditions and also with other solid phases and under different fluid compositions (e.g., Huckenholz \& Yoder, 1971; Gustafson, 1973; Suwa et al., 1976; Shoji, 1977; Taylor \& Liou, 1978; Wykes et al., 2008). In 
addition to phase-equilibrium research, calorimetric measurements (i.e., adiabatic calorimetry and differential scanning calorimetry - DSC) were carried out on a synthetic andradite to determine its $C_{p}$ behavior between $8 \mathrm{~K}$ and $1000 \mathrm{~K}$ (Robie et al., 1987). Low temperature $C_{p}$ results allow the standard third-law entropy, $S^{\mathrm{o}}$, at $298.15 \mathrm{~K}$ to be calculated. These various experimental results have been used to "optimize" the thermodynamic properties of andradite, as has been done in different internally consistent thermodynamic databases (Gottschalk, 1997; Chatterjee et al., 1998; Holland \& Powell, 1998; 2011).

The vibrational spectrum of andradite has been studied by Raman polarized single-crystal (Kolesov \& Geiger, 1998) and IR reflectance single-crystal (McAloon \& Hofmeister, 1993) spectroscopy. The heat capacity and entropy of andradite can be calculated under model assumptions, together with other physical property input data, using such vibrational spectra (i.e., Kieffer, 1979a, b; 1980), as also done later by Madon et al. (1991) and Chopelas (2006).

The crystal structures of both natural (Novak \& Gibbs, 1971; Adamo et al., 2011) and synthetic andradite (Armbruster \& Geiger, 1993) have been studied by Xray single-crystal diffraction and the two types are very similar structurally. The magnetic behavior of andradite from Val Malenco, Italy, was studied by low temperature ${ }^{57} \mathrm{Fe}$-Mössbauer measurements (Murad, 1984), which show that the electron spins of the $\mathrm{Fe}^{3+}$ cations order from the paramagnetic to antiferromagnetic state with a Néel transition temperature of $11.5 \pm 0.1 \mathrm{~K}$. The nature of this transition has also been investigated via ab initio calculations (Meyer et al., 2010). Finally, the UV/VIS spectrum of andradite has been measured multiple times (e.g., Manning, 1969; Burns, 1993; Adamo et al., 2009; Taran \& Langer, 2000) focusing on the $\mathrm{Fe}^{3+}-\mathrm{O}$ chargetransfer as well as on the spin-forbidden bands.

One could possibly think that there is little left to research in terms of andradite's key physical properties. However, this is not the case and several important issues still need to be addressed and clarified. They are: i) It needs to be investigated if there could be small differences in thermodynamic, and here $C_{p}$, behavior between synthetic and natural andradite crystals as well as among natural crystals themselves. This general question has not been carefully researched in the mineral sciences. In terms of another Ca-bearing garnet, grossular, $\mathrm{Ca}_{3} \mathrm{Al}_{2} \mathrm{Si}_{3} \mathrm{O}_{12}$, which is one of the few silicates to be studied extensively in this regard, there are small but measurable differences in $C_{p}$ behavior at low temperatures between natural and synthetic crystals (Dachs et al., 2012a). Small but meaningful differences in $S^{0}$ result $(\sim 254$ vs. $\sim 260$ $\mathrm{J} / \mathrm{mol} \cdot \mathrm{K}$, respectively). It is not known if this could be the case with andradite, which shares mineralogical and petrological similarities with grossular, because both garnets can occur in similar rock types and crystallize under similar $P-T$ conditions. And here, the issue of careful sample characterization plays an essential role. Most older (i.e., say roughly pre 1990) calorimetric investigations undertook only rudimentary characterization measurements (i.e., optical and X-ray examination and perhaps a microprobe analysis), at least by today's standards, of the mineral(s) to be studied. These results were, moreover, in general, cursorily reported. Thus, it is essentially impossible to be able to make quantitative crystal-chemical and structural interpretations of the macroscopic $C_{p}$ results; ii) The precise thermal magnetic-phase-transition behavior of andradite needs further study. Here, it must be noted that lowtemperature adiabatic calorimetry $C_{p}$ measurements are/were often not made below about $8 \mathrm{~K}$. This is the case for andradite (Robie et al., 1987) as well as other transition-metal-bearing garnets. They show cooperative magnetic transitions whose thermal signatures extend below $8 \mathrm{~K}$ and approach $0 \mathrm{~K}$ (Klemme et al., 2005; Dachs et al., 2009; Dachs et al., 2012b), and iii) Improvements in power-compensated DSC methods allow more precise determinations of $C_{p}(T)$ from roughly 150 or $300 \mathrm{~K}$ to $900-1000 \mathrm{~K}$ compared to data obtained using first-generation devices and measurements made from the 1970s through the 1980s (see discussion in, e.g., Bosenick et al., 1996, for the case of grossular).

In light of these various issues, this work focuses on the thermophysical $C_{p}$ behavior of different well-characterized synthetic and natural andradite samples from $2 \mathrm{~K}$ to $900 \mathrm{~K}$. The calorimetric results are also considered in terms of the IR and UV/VS spectra and compositional data.

\section{Analytical and experimental methods}

\subsection{Natural and synthetic samples and optical examination}

Four natural, nearly end-member composition andradite single crystals from different localities and two synthetic polycrystalline samples were investigated by calorimetry. They are listed and described in Table 1 . The much larger natural crystals were prepared as small platelets, polished on both sides, of roughly $0.5 \mathrm{~mm}$ thickness for the compositional (microprobe), spectroscopic (some additional platelets were made thinner to allow IR characterization) and calorimetric measurements.

All andradites were examined under binocular and polarizing microscopes. The optical properties (e.g., possible presence of inclusions and possible anisotropy) of the single-crystal platelets were examined and photographed. Photos of the various crystals, excepting the finegrained polycrystalline sample SD23, are shown in Figs. S1 and S2 (freely available online as supplementary material linked to this article on the GSW website of the journal: https://pubs.geoscienceworld/eurjmin/). The synthesis and characterization of sample And \#27 (Fig. 1e and 1f) is described in Armbruster \& Geiger (1993). They studied its crystal structure at five different temperatures between $100 \mathrm{~K}$ and $500 \mathrm{~K}$, in addition to measuring its ${ }^{57} \mathrm{Fe}$ Mössbauer and IR (3800 to $3200 \mathrm{~cm}^{-1}$ ) spectra. The 
Table 1. Description of the natural and synthetic andradite samples used for study.

\begin{tabular}{|c|c|c|}
\hline Sample & $\begin{array}{l}\text { Locality (donor/source) or } \\
\text { synthesis conditions }\end{array}$ & $\begin{array}{l}\text { Sample description, additional very minor phases, mass used for PPMS measurements and } \\
\text { optical behavior }\end{array}$ \\
\hline VM-11 & Val Malenco, Italy (R. Boccio) & $\begin{array}{l}\text { Light green transparent single crystal }(11.92 \mathrm{mg}) \text { Inclusions of long hair-like fibers } \\
\text { (serpentine?). Anisotropic. }\end{array}$ \\
\hline 4282 & Madagascar(?) (zoultier.com) & Light green transparent single crystal $(24.94 \mathrm{mg})$. Anisotropic. \\
\hline $113-102$ & $\begin{array}{l}\text { Dobrovka, Nizhniy Tagil, } \\
\quad \text { Russia (C. Ferraris) }\end{array}$ & $\begin{array}{l}\text { Light green transparent single crystal }(35.95 \mathrm{mg}) \text {. Inclusions of very long hair-like } \\
\text { serpentine fibers. Isotropic. }\end{array}$ \\
\hline Bal-1 & Balochistan, Pakistan & $\begin{array}{l}\text { Light green transparent euhedral single crystal showing }\left\{\begin{array}{lll}1 & 1 & 0\end{array}\right\} \text { faces }(6.13 \mathrm{mg}) \text {. Tiny } \\
\text { inclusions of minor Cr-bearing magnetite and small areas containing serpentine. } \\
\text { Anisotropic. }\end{array}$ \\
\hline And \#27 & $\begin{array}{l}T=1200^{\circ} \mathrm{C} \& P=20 \mathrm{kbar} \text {, with } \\
\mathrm{PtO}_{2}(\text { Armbruster \& Geiger, } \\
1993)\end{array}$ & $\begin{array}{l}\text { Partly loose synthetic polycrystalline product with some individual crystals up to roughly } \\
300 \mu \mathrm{m} \text { in size }(11.09 \mathrm{mg}) \text {. Yellow greenish to golden in color. Small amount very fine } \\
\text { Pt. Isotropic }\end{array}$ \\
\hline SD23 & $\begin{array}{l}T=900^{\circ} \mathrm{C} \& P=15 \text { kbar, with } \\
\mathrm{PtO}_{2}\end{array}$ & $\begin{array}{l}\text { Yellow-green hard polycrystalline pellet with some individual crystals up to roughly } \\
200 \mu \mathrm{m} \text { in size }(13.20 \mathrm{mg}) \text {. Possible trace of wollastonite. Isotropic. }\end{array}$ \\
\hline
\end{tabular}

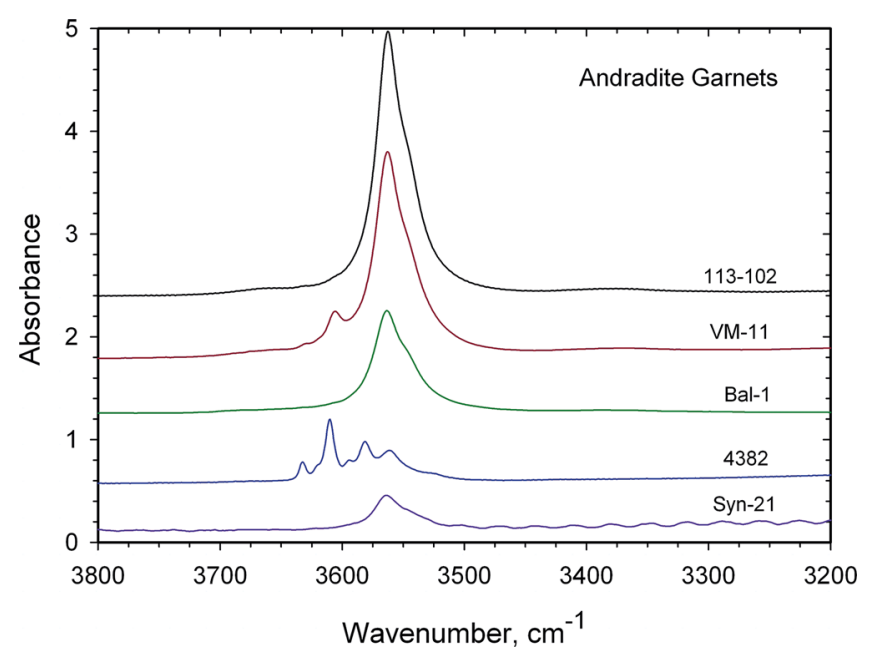

Fig. 1. FTIR single-crystal spectra of four natural andradite crystals and synthetic And \#27. Note that most samples are characterized by an intense slightly asymmetric band with a maximum intensity at $3563 \mathrm{~cm}^{-1}$. This band may represent the hydrogarnet substitution (Geiger \& Rossman, 2018).

second andradite sample, SD23, was synthesized in a manner similar to And \#27 from a glass in a pistoncylinder device (in a large Au capsule at $P=15 \mathrm{kbar}$ and $T=900{ }^{\circ} \mathrm{C} . \mathrm{PtO}_{2}$ was used in both syntheses in order to maintain a high oxygen fugacity in the charge.

\subsection{Microprobe analysis}

The composition of the natural andradite platelets was determined using a JEOL microprobe at Kiel University, Germany, and WDS methods were applied under conditions of $15 \mathrm{kV}$ and $15 \mathrm{nA}$ with a focused beam size of $1 \mu \mathrm{m}$ as done in other studies on garnet (e.g., Dachs et al., 2012a, b). Due to the generally small sizes (less than roughly $40 \mu \mathrm{m}$ ) of most crystals and difficulties in obtaining quantitative microprobe results on synthetic garnets (Dachs et al., 2009; Fournelle \& Geiger, 2010), the synthetic andradites were not measured. The standards used for analysis were corundum for Al, wollastonite for $\mathrm{Ca}$ and $\mathrm{Si}$, and a natural fayalite-rich olivine for $\mathrm{Fe}, \mathrm{V}$ metal for $\mathrm{V}$, chromite for $\mathrm{Cr}$, tephroite for $\mathrm{Mn}$, rutile for $\mathrm{Ti}$, and forsterite for $\mathrm{Mg}$. The data correction program employed was CITZAF.

\subsection{X-ray powder diffraction}

X-ray powder patterns were recorded for the two synthetic samples. Sample And \#27 was measured between 5 and $110^{\circ} 2 \theta$ with a step size of $0.02^{\circ}$ with $20 \mathrm{sec} /$ step with a Siemens D-500 diffractometer (Salzburg) having a graphite secondary monochromator with $\mathrm{Cu} K \alpha$ radiation $(40 \mathrm{kV}, 35 \mathrm{~mA})$. Synthetic andradite SD23 was measured over the $2 \theta$ range $10^{\circ}$ to $90^{\circ}$ using a Siemens D5000 diffractometer (Kiel) with $\mathrm{Cu} K \alpha$ radiation $(40 \mathrm{kV}$, $30 \mathrm{~mA}$ ). Diffraction patterns were recorded with $0.02^{\circ}$ $2 \theta$ increments and up to $30 \mathrm{~s}$ counting time per step. Silicon powder NBS SRM 640b was used as an external calibration standard. In both cases, we estimate that minor phases, if well crystalline, are detectable above about the $0.5 \%$ level.

\subsection{FTIR spectroscopy}

The FTIR spectra were collected on five single-crystal platelets (Fig. 1), doubly polished on both sides, using apertures of either 50 or $200 \mu \mathrm{m}$ diameter. The main purpose of the IR measurements was to characterize any structural $\mathrm{OH}^{-}$in the garnet. The preparation and experimental measuring conditions are similar to those described in Geiger \& Rossman (2018). Spectra were collected between 10,000 and $2,000 \mathrm{~cm}^{-1}$ using a ThermoNicolet iS50 FTIR spectrometer (at Caltech). Efforts were made to make measurements on different parts of the natural crystal platelets, and also on those minor areas that appeared to have inclusion phases. 


\subsection{UV/VIS optical absorption single-crystal spectroscopy}

The UV/VIS single-crystal spectrum of one of the larger synthetic crystals taken from the sample And \#27 was recorded in the 380 to $1100 \mathrm{~nm}$ range at about $1.5 \mathrm{~nm}$ resolution. This was done using a homebuilt microspectrometer system consisting of a 1024-element $\mathrm{Si}$ diode-array detector coupled to a $1 / 3$ meter grating spectrometer system attached via fiber optics to a highly modified NicPlan infrared microscope containing a calcite polarizer (at Caltech). Spectra in the 300 to $480 \mathrm{~nm}$ region were also obtained with a homebuilt system with an Ocean Optics spectrometer and a deuterium lamp.

\subsection{Calorimetric measurements}

\subsubsection{Low-temperature relaxation calorimetry}

Low-temperature (i.e., 2 to $300 \mathrm{~K}$ ) heat-capacity behavior was investigated with the Physical Properties Measurement System (PPMS) constructed by Quantum Design ${ }^{\circledR}$ (e.g., Lashley et al., 2003; Dachs \& Bertoldi, 2005). The relaxation calorimeter and its experimental set-up and method have been described a number of times, including investigations on garnet (e.g., Dachs et al., 2012a; 2012b). Thus, only a brief summary is given here.

Heat capacity was measured at 60 different temperatures and three times at each temperature on cooling from $300 \mathrm{~K}$ with a logarithmic spacing. A complete PPMS experiment to determine $C_{p}$ comprises an 'addenda run' and a 'sample run'. The first measurement determines the heat capacity of the empty sample platform of the calorimeter plus Apiezon $\mathrm{N}$ grease that facilitates thermal contact between the platform and the sample \pm container. In the second measurement, the sample \pm container is included and the heat capacity of the whole ensemble is measured. The net heat capacity of the sample \pm container is then given by the difference between the two measurements. An uncertainty of $\pm 0.02 \mathrm{mg}$ for the sample weight was adopted for converting the PPMS data from units of $\mu \mathrm{J} \cdot \mathrm{K}^{-1}$ to units of $\mathrm{J} / \mathrm{mol} \cdot \mathrm{K}$.

The natural andradite crystal platelets were directly mounted onto the measurement platform for $C_{p}$ determination. They weighed between 6 and $36 \mathrm{mg}$ (Table 1). The molar mass of each natural sample was calculated using the microprobe analysis results. The two synthetic samples were measured by enclosing the polycrystalline material/ powder in Al foil. Their sample masses were $11.09 \mathrm{mg}$ (And \#27) and $13.20 \mathrm{mg}$ (SD23). The use of polished single crystals permits better sample coupling during PPMS measurement (Dachs \& Bertoldi, 2005; Benisek \& Dachs, 2008). Sample coupling is defined as the ratio $100 K_{g} /\left(K_{g}+K_{w}\right)$, where $K_{g}$ is the thermal conductance between the sample and the measurement platform and $K_{w}$ is the thermal conductance of the wires that attach the platform to the puck frame of the calorimeter (see Hwang et al., 1997; Lashley et al., 2003; Dachs \& Bertoldi, 2005, for more details). The closer the sample coupling is to $100 \%$, the better the thermal conductance between the sample platform and the sample, which ensures a more robust heat-capacity determination via relaxation calorimetry. Experience indicates that an accuracy of about 0.2 (or even 0.1$) \%$ above $\sim 30 \mathrm{~K}$ in $C_{p}$ and the standard entropy, $S^{\circ}$, can be achieved for single crystals (Benisek \& Dachs, 2008; Dachs \& Geiger, 2018). It is between about $0.2 \%$ and $0.5 \%$ for measurements on powders (weighing about $10-20 \mathrm{mg}$ ) contained in thin Al-metal foil.

\subsubsection{DSC measurements}

Heat-capacity determinations were made in two different DSC laboratories, namely at Kiel and Salzburg Universities. The labs and experimental set-ups have already been described (for the Kiel laboratory see Bosenick et al., 1996, and for the Salzburg laboratory see Benisek et al., 2010 or Dachs et al., 2012a, 2012b). The $C_{p}$ measurements were made between about 150 and $950 \mathrm{~K}$ in the Kiel lab using a power-compensated Perkin Elmer DSC 7 device and between about 300 and $750 \mathrm{~K}$ in the Salzburg lab using a Perkin Elmer Diamond DSC. Briefly, samples were contained in thin $\mathrm{Au}$ (Kiel) or $\mathrm{Al}$ (Salzburg) pans and lids, with the former containing a loose polycrystalline powder or a single-crystal platelet. A $C_{p}$ determination usually consisted of three or more separate measurements of a blank, a reference and a sample measurement. Before a sample measurement, the DSC was calibrated and checked with a reference run using a synthetic single-crystal platelet of corundum $(31.764 \mathrm{mg})$. Its heat-capacity values were taken from a National Bureau of Standards Certificate (Ditmars et al., 1982). Each garnet sample was measured three times in this manner. These data were averaged to obtain the final $C_{p}(T)$.

\subsubsection{Calorimetric data evaluation}

The standard molar entropy at $298.15 \mathrm{~K}$ (i.e., third-law entropy), $S^{\mathrm{o}}$, was calculated from the final averaged $C_{p}$ data set using the Mathematica ${ }^{\circledR}$ functions NIntegrate and Interpolation for linear interpolation between data points via:

$S^{\circ}-S^{T=0 K}=\int_{0}^{298.15 K} \frac{C_{P}}{T} d T$,

assuming $S^{T=0 K}=0$. The $C_{p}$ behavior for the minor lowtemperature interval from $2 \mathrm{~K}$ down to about $0 \mathrm{~K}$, which was not measured, was extrapolated using results from the synthetic sample SD23. This interval corresponds to $S^{0-2 K}=1.3 \mathrm{~J} / \mathrm{mol} \cdot \mathrm{K}$ and this value was considered the same for all other studied andradites.

The heat capacity at constant volume, $C_{v}$ of a crystalline substance at a given temperature consists of a number of contributions and can be expressed as:

$C_{v}=C_{\mathrm{vib}}+C_{\mathrm{mag}}+C_{\text {Schottky }}+C_{\mathrm{el}}+C_{\mathrm{def}}+\ldots$

where $C_{\mathrm{vib}}$ is the vibrational (or lattice or phonon) contribution, $C_{\text {mag }}$ the cooperative magnetic, $C_{\text {Schottky }}$ the Schottky, $C_{\mathrm{el}}$ the conduction electronic, and $C_{\mathrm{def}}$ the defect 
contribution (Gopal, 1966; Grimvall, 2001). In the case of most silicates, the last two terms can normally be ignored. Furthermore, for $\mathrm{Fe}^{3+}$, with one $d$ electron distributed over each of the five different energy $d$-orbitals, there can be no spin-orbit interaction involving the ground state orbital that can lead to a Schottky anomaly ( $c f$. the case for $\mathrm{Fe}^{2+}$ and $\mathrm{Mn}^{2+}$ in garnet in Dachs et al., 2012b, and Dachs et al., 2009, respectively). This means that for andradite $C_{v} / C_{p}$ consists of only $C_{\mathrm{vib}}$ and $C_{\mathrm{mag}}$ components. They can be separated from one another and analyzed using appropriate lattice dynamic models.

We did this using the single-parameter phonon dispersion model of Komada \& Westrum (1997), which appears to describe well the $C_{\mathrm{vib}}(T)$ behavior of the two silicates olivine and garnet (Dachs et al., 2007, 2009, $2012 b$ ). The calculation is based on a model density of states that is expressed as a function of a single parameter, the so-called characteristic temperature, $\theta_{\mathrm{KW}}$. This parameter can be determined by fitting the model to experimental $C_{p}$ data (Komada \& Westrum, 1997; Dachs et al., 2007, 2009) at a temperature above, for example, a magnetic phase transition, where $C_{p}$ is not affected by nonlattice heat-capacity contributions. At these higher temperatures, $\theta_{\mathrm{KW}}$ obtains a nearly constant value and it can be used to calculate the lattice/vibrational heatcapacity, $C_{\mathrm{vib}}$, behavior in the lower temperature region that is affected by the phase transition. The magnetic heat capacity, $C_{\mathrm{mag}}$, is then computed via $C_{\mathrm{mag}}=C_{v}-C_{\mathrm{vib}}$. $C_{v}$ is calculated from the experimental $C_{p}$ data by applying the standard relationship:

$C_{P}-C_{v}=\frac{V_{o} T \beta^{2}}{K_{T}}$

where $V_{o}$ is the molar volume, $T$ the temperature, $\beta$ the isobaric thermal expansion and $K_{T}$ the isothermal compressibility.

The values for volume, $V$ (using $a_{\mathrm{o}}=12.054 \AA$ ), thermal expansion, $\alpha,\left(20+0.01 \cdot T 10^{-6} / \mathrm{K}\right)$ and bulk modulus, $K_{T}$ $(162 \mathrm{GPa})$, of andradite were taken from Chopelas (2006). This Komada-Westrum model was applied to the $C_{p}$ data of synthetic SD23 andradite, which is considered to best represent end-member andradite.

\section{Results}

\subsection{Sample description and optical properties}

All natural non-heated andradites have a similar light yellow-green color (Fig. S1 and Table 1). The garnet crystals can contain very minor included solid phases. Sample 113102 from Dobrovka, Nizhniy Tagil, Russia, contains very small amounts of chrysotile occurring as fine hair-like fibers (see Phillips \& Talantsev, 1996, for a full description), as shown in Fig. S1g. Sample VM-11, from the well-known demantoid locality at Val Malenco, Italy, also appears to contain very minor amounts of a fine hair-like phase (see also Adamo et al., 2009). Sample Bal-1, occurring as euhedral crystals with elongated $\{110\}$ faces, from
Table 2a. Microprobe results for the four natural andradites expressed in oxide weight percent.

\begin{tabular}{lrrrr}
\hline Oxides & VM-11 & 4282 & $113-102$ & Bal-1 \\
\hline $\mathrm{SiO}_{2}$ & 36.14 & 35.67 & 35.59 & 35.52 \\
$\mathrm{TiO}_{2}$ & 0.04 & 0.01 & 0.02 & 0.02 \\
$\mathrm{Al}_{2} \mathrm{O}_{3}$ & 0.09 & 0.02 & 0.02 & 0.04 \\
$\mathrm{Cr}_{2} \mathrm{O}_{3}$ & 0.02 & 0.01 & 0.01 & 0.01 \\
$\mathrm{FeOtot.}$ & 27.70 & 28.13 & 28.22 & 27.93 \\
$\mathrm{MnO}$ & 0.05 & 0.03 & 0.04 & 0.21 \\
$\mathrm{MgO}$ & 0.16 & 0.12 & 0.08 & 0.04 \\
$\mathrm{CaO}$ & 33.66 & 33.12 & 32.97 & 33.03 \\
$\mathrm{Na}_{2} \mathrm{O}$ & 0.06 & 0.05 & 0.07 & 0.07 \\
$\mathrm{~V}_{2} \mathrm{O}_{3}$ & 0.05 & 0.05 & 0.04 & 0.05 \\
$\mathrm{Total}$ & 97.97 & 97.21 & 97.07 & 96.91 \\
\hline
\end{tabular}

Balochistan, Pakistan, contains, as well, very small amounts of chrysotile and, in addition, tiny Cr-bearing magnetite crystals, as described by Adamo et al. (2015). Sample 4282, whose locality is unknown to us (this andradite has a similar color and optical behavior and a very similar IR $\mathrm{OH}^{-}$-band spectrum to an andradite reported from Madagascar Pezzotta et al., 2011, and Adamo et al., 2011), appears to be largely free of solid-inclusion phases. Of the different garnets that were studied, only the natural sample 113-102 and the two synthetics are optically isotropic. The other crystals show rather complex anisotropic behavior similar to that observed in many natural grossulars (e.g. Dachs et al., 2012a), as shown in Fig. S2.

\subsection{Microprobe analysis}

The compositions of the natural andradite samples, based on about 30 to 40 point analyses taken from a line traverse across each platelet, which were averaged to obtain the final composition, are given in Table 2a. The crystals showed no major compositional zonation. The crystalchemical formulae, broken down into various end-member garnet components, were calculated using the program of Locock (2008) and are given in Table 2b. Slight deviations from strict end-member andradite composition are noted. Based on the formulation of Locock (2008), samples VM11 and Bal-1 show 1.0 to $2.5 \%$ of a "remainder component" that could not be assigned precisely to any standard garnet component. Difficulties in obtaining exact garnet stoichiometry are probably due to several factors. These include structural $\mathrm{OH}^{-}$(see below), possible recording of minor solid inclusions in a few of the random point measurements, difficulties in calculating $\mathrm{Fe}^{3+} /\left(\mathrm{Fe}^{2+}+\mathrm{Fe}^{3+}\right)$ ratios precisely using olivine with $\mathrm{Fe}^{2+}$ as a $\mathrm{Fe}$ standard, and finally, normal analytical uncertainty. In summary, we consider the microprobe results to be good and all natural samples are considered to be greater than about $99 \mathrm{~mol} \%$ andradite in composition.

\subsection{X-ray powder diffraction}

The X-ray powder diffractogram of the synthetic sample And \#27 showed very small amounts of fine-grained Pt. It 
Table $2 \mathrm{~b}$. Composition of the natural garnets expressed in terms of end-member components (mol\%) following the crystal-chemical scheme of Locock (2008).

\begin{tabular}{|c|c|c|c|c|c|}
\hline Garnet & Composition & VM-11 & 4282 & $113-102$ & Bal-1 \\
\hline Schorlomite & $\left\{\mathrm{Ca}_{3}\right\}\left[\mathrm{Ti}_{2}\right]\left(\mathrm{SiFe}_{2}\right) \mathrm{O}_{12}$ & & & & 0.01 \\
\hline 'Schorlomite-Al' & $\left\{\mathrm{Ca}_{3}\right\}\left[\mathrm{Ti}_{2}\right]\left(\mathrm{SiAl}_{2}\right) \mathrm{O}_{12}$ & & & & 0.05 \\
\hline 'NaTi garnet' & $\left\{\mathrm{Na}_{2} \mathrm{Ca}\right\}\left[\mathrm{Ti}_{2}\right]\left(\mathrm{Si}_{3}\right) \mathrm{O}_{12}$ & 0.13 & 0.04 & 0.06 & \\
\hline Majorite & $\left\{\mathrm{Mg}_{3}\right\}[\mathrm{SiMg}]\left(\mathrm{Si}_{3}\right) \mathrm{O}_{12}$ & 0.23 & 0.19 & & \\
\hline Goldmanite & $\left\{\mathrm{Ca}_{3}\right\}\left[\mathrm{V}_{2}\right]\left(\mathrm{Si}_{3}\right) \mathrm{O}_{12}$ & 0.18 & 0.17 & 0.15 & 0.16 \\
\hline Uvarovite & $\left\{\mathrm{Ca}_{3}\right\}\left[\mathrm{Cr}_{2}\right]\left(\mathrm{Si}_{3}\right) \mathrm{O}_{12}$ & 0.06 & 0.02 & 0.03 & 0.04 \\
\hline Pyrope & $\left\{\mathrm{Mg}_{3}\right\}\left[\mathrm{Al}_{2}\right]\left(\mathrm{Si}_{3}\right) \mathrm{O}_{12}$ & & 0.09 & 0.10 & \\
\hline Grossular & $\left\{\mathrm{Ca}_{3}\right\}\left[\mathrm{Al}_{2}\right]\left(\mathrm{Si}_{3}\right) \mathrm{O}_{12}$ & 0.44 & & & \\
\hline Andradite & $\left\{\mathrm{Ca}_{3}\right\}\left[\mathrm{Fe}_{2}\right]\left(\mathrm{Si}_{3}\right) \mathrm{O}_{12}$ & 96.57 & 98.99 & 99.08 & 98.50 \\
\hline 'Khoharite' & $\left\{\mathrm{Mg}_{3}\right\}\left[\mathrm{Fe}_{2}\right]\left(\mathrm{Si}_{3}\right) \mathrm{O}_{12}$ & & & 0.24 & \\
\hline Remainder & & 2.39 & 0.50 & 0.35 & 1.25 \\
\hline Total & & 100.00 & 100.00 & 100.10 & 100.01 \\
\hline
\end{tabular}

originates from the $\mathrm{PtO}_{2}$ that was used in the high $P-T$ synthesis procedure, as described by Armbruster \& Geiger (1993). Sample SD23 may have a trace of wollastonite.

\subsection{FTIR spectroscopy}

The FTIR single-crystal spectra of the studied andradite crystals are shown in Fig. 1 in the wavenumber region from 3800 to $3200 \mathrm{~cm}^{-1}$. The spectra presented here are considered to be free of any inclusions and, thus, representative of structural $\mathrm{OH}^{-}$in the andradite. Samples Bal-1, 113-102 and And \#27 are characterized by a main asymmetric $\mathrm{OH}^{-}$stretching band located at $3563 \pm 1 \mathrm{~cm}^{-1}$. This mode energy agrees perfectly with the IR results in Adamo et al. $(2009,2011)$, but is different from that stated in Amthauer \& Rossman (1998), where a value of $3555 \mathrm{~cm}^{-1}$ is presented (however, our reanalysis of these latter spectra gives a value of $3563 \mathrm{~cm}^{-1}$ ). Sample VM-11 gives spectra with one notable additional peak at $3605 \mathrm{~cm}^{-1}$ (see also Adamo et al., 2009, 2011). The spectrum of sample 4282 is radically different from the others, as it contains multiple low-intensity $\mathrm{OH}$ bands ( $c f$., Amthauer \& Rossman, 1998; Adamo et al., 2011). The assignment for the asymmetric band at $3563 \mathrm{~cm}^{-1}$ is to a hydrogarnet substitution (Geiger \& Rossman, 2018), whereas the other bands must represent $\mathrm{OH}^{-}$in an another structural site or cluster.

We were also able to record a few spectra on two samples where additional weak, apparently non-garnetrelated $\mathrm{OH}^{-}$bands, could be observed. Mostly, but not always, these bands occurred in those small areas of the natural crystals that were more optically turbid and appeared to contain inclusion phases. For example, one measuring spot on the crystal VM-11 produced a spectrum showing an asymmetric band located at about $3678 \mathrm{~cm}^{-1}$. This band can be best assigned to $\mathrm{OH}^{-}$in talc (Petit et al., 2004; Parry et al., 2007 - we note, further, that this band may also be present in the spectrum of sample GRR 1263, San Benito Co., CA, of Amthauer \& Rossman, 1998). We did not observe any overt $\mathrm{OH}^{-}$bands that could be assigned to chrysotile in, for example, andradite 113-102, even though we made measurements on regions that
Table 3. Calculated $\mathrm{H}_{2} \mathrm{O}$ concentrations from $\mathrm{OH}$ bands from IR spectra (Fig. 1) of andradite in ppm based on calibrations made on other garnets (see Rossman, 2006).

\begin{tabular}{lrrrr}
\hline \multirow{2}{*}{ Sample } & $\begin{array}{l}\text { Total integrated } \\
\text { absorbance per cm }\end{array}$ & Grossular & Pyrope & Spessartine \\
\cline { 3 - 5 } & 17303 & 2422 & 4153 & 2163 \\
\hline Bal-1 & 3208.5 & 449 & 770 & 401 \\
$113-102$ & 789.0 & 110 & 189 & 99 \\
4282 & 407.7 & 57 & 98 & 51 \\
And \#27 & 2830.2 & 396 & 679 & 354 \\
VM-11 & & & & \\
\hline
\end{tabular}

appeared to contain fine hair-like inclusions. Chrysotile and lizardite show $\mathrm{OH}^{-}$bands at $3691-3696 \mathrm{~cm}^{-1}$ and $3647-3650 \mathrm{~cm}^{-1}$ and a possible third one around $3685 \mathrm{~cm}^{-1}$ (Post \& Borer, 2000). We do not have an explanation for the lack of observable $\mathrm{OH}^{-}$bands that could be related to the possible presence of minor fine, hair-like chrysotile.

The intensities of the $\mathrm{OH}^{-}$bands allow the amount of structural " $\mathrm{H}_{2} \mathrm{O}$ " in the garnet to be determined. There is no direct IR calibration for $\mathrm{OH}^{-}$in andradite and, thus, the estimated $\mathrm{H}_{2} \mathrm{O}$ amounts must be based on calibrations made for other garnets, namely grossular, pyrope or spessartine (Rossman, 2006). The total integrated absorbance per $\mathrm{cm}$ of the $\mathrm{OH}^{-}$bands of the three andradite samples, along with their respective calculated $\mathrm{H}_{2} \mathrm{O}$ contents in ppm, based on three reference garnets, are given in Table 3. They range between about $0.006 \mathrm{wt} \%$ for And \#27 to $0.24 \mathrm{wt} \%$ for Bal-1 using the calibration for grossular. Using the calibration for spessartine gives roughly similar $\mathrm{H}_{2} \mathrm{O}$ concentrations for the different crystals, while that for pyrope would give considerably higher values.

\subsection{UV/VIS spectroscopy}

Figure 2 shows UV/VIS spectra between 380 to $1100 \mathrm{~nm}$ of three andradite garnets, namely synthetic And \#27 and two representative natural crystals (GRR 48 and GRR 3137) from the collection of G.R. Rossman. The 


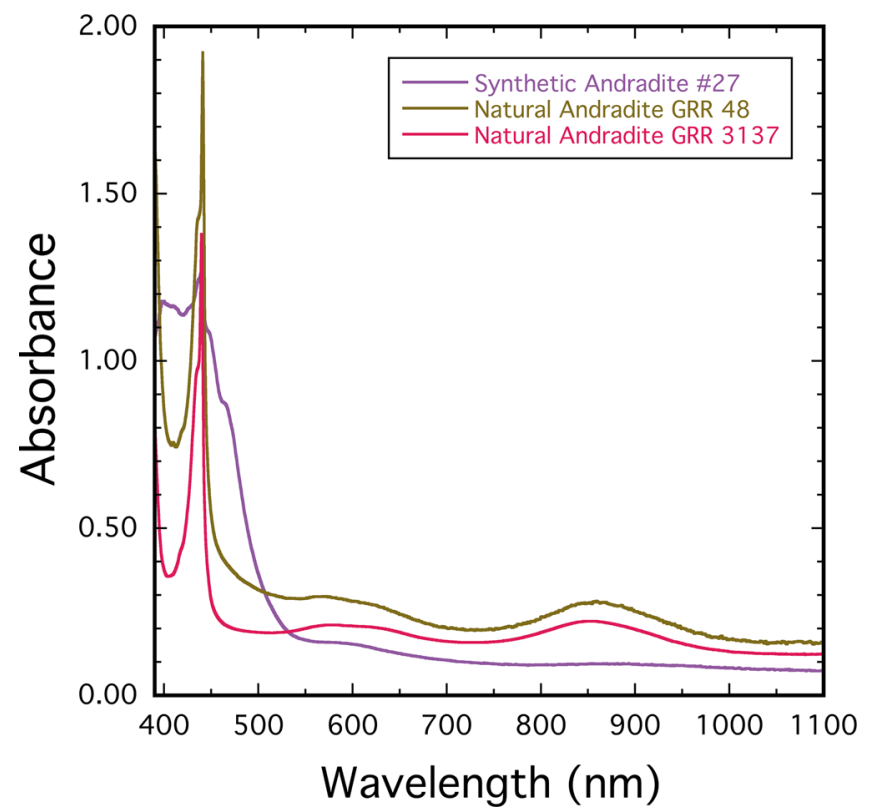

Fig. 2. UV/VIS single-crystal absorption spectra of synthetic And \#27 and two natural andradite crystals GRR-48 and GRR-3137 from $390 \mathrm{~nm}$ to $1100 \mathrm{~nm}$. An intense $\mathrm{Fe}^{3+}-\mathrm{O}$ charge transfer absorption band is centered at wavelengths below $400 \mathrm{~nm}$ and its lower-energy flank is shown. Natural nearly end-member andradite crystals are characterized by a sharp asymmetric spin-forbidden band with a maximum intensity at $440.1 \mathrm{~nm}\left(22,700 \mathrm{~cm}^{-1}\right)$ and a slightly higher energy shoulder. The spectrum of synthetic And \#27 is different in appearance.

absorption features for the natural crystals are very similar to those described in the literature (e.g., Manning, 1969; Burns, 1993; Adamo et al., 2009; Taran \& Langer, 2000). A very intense $\mathrm{Fe}^{3+}-\mathrm{O}$ charge-transfer band dominates andradite's spectrum at lower wavelengths. Only a part of the low-energy flank of this intense band is observable in Fig. 2. Superimposed on this flank is a sharp asymmetric peak at about $440 \mathrm{~nm}$ and at higher wavelengths two weak broad bands are located. These spectroscopic features represent various spin-forbidden transitions, as discussed in Taran \& Langer (2000). They analyzed the exact fitting of the absorption features and made band assignments and crystal-chemical interpretations.

What is slightly new and of interest, here, is the spectrum of sample And \#27. It shows different absorption behavior that cannot be precisely interpreted. It is notable that the color of this synthetic crystal is also slightly different from those of the natural andradites (Fig. S1), being more golden in color rather than light green. These UV/VIS spectroscopic results are relevant in terms of the magnetic phase transition behavior of andradite as discussed below.

\subsection{Low-temperature ( 0 to $300 \mathrm{~K}$ ) heat-capacity behavior and standard third-law entropy of andradite}

The raw $C_{p}$ data for the two synthetic polycrystalline andradites (SD23 and And \#27) and the four natural andradite platelets are given in Appendix 1 (supplementary material). Interpolated $C_{p}$ behavior is shown in Fig. 3. Table 4 (bottom) summarizes the salient results of the PPMS and DSC measurements. In terms of lowtemperature relaxation calorimetry, sample coupling lies in the range of $98-100 \%$. For the natural crystals 4282 , Bal-1, VM-11 and the synthetic sample SD23, the agreement between PPMS- and DSC-measured heat capacity around ambient temperature was excellent with maximum deviations of $0.5 \%$. The sample 113-102 showed a slightly larger deviation of $1 \%$ and, therefore, its PPMS $C_{p}$ data was adjusted (see Dachs \& Benisek, 2011). No data adjustment was made for the other samples. The $C_{p}$ values for And $\# 27$ are slightly different from those of the other samples because of the presence of a small amount of Pt. These data were not used to calculate $S^{\circ}$, but the low-temperature $C_{p}$ magnetic behavior of the sample is analyzed below in connection with its UV/VIS spectrum.

The individual standard third-law entropy values for the various andradite samples studied are listed in Table 4. They range between $321.8 \pm 2.2$ and $325.7 \pm 2.2 \mathrm{~J} / \mathrm{mol} \cdot \mathrm{K}$ and, thus, overlap within experimental error. We note, however, that andradite Bal-1 has the highest $S^{\circ}$ with a value of $325.7 \pm 2.2 \mathrm{~J} / \mathrm{mol} \cdot \mathrm{K}$. This very slightly larger value might reflect the larger $\mathrm{OH}^{-}$concentration in this andradite (Table 3) compared to the other crystals. The hydrogarnet substitution should, based on calorimetric work on katoite $\left(\mathrm{Ca}_{3} \mathrm{Al}_{2} \mathrm{O}_{12} \mathrm{H}_{12}\right.$ - Geiger et al., 2012), lead to higher $C_{p}$ and $S^{\circ}$ values in silicate garnet.

\subsection{High-temperature ( 300 to $900 \mathrm{~K}$ ) heat-capacity behavior of andradite}

The raw DSC data for the various studied andradite samples are also compiled in Appendix 1 that lists the mean $C_{p}$ values and standard deviation. Three samples were used for extensive DSC measurements to higher temperatures, namely synthetic SD23, 113-102 and VM11. Sample SD23 was studied at Kiel and Salzburg and the latter two only in Salzburg. The $C_{p}$ values for SD23, measured in Kiel, 113-102 and VM-11 are shown in Fig. 4. The agreement among the three data sets is excellent and $C_{p}(T)$ is the same within $\pm 0.5 \%$. This uncertainty probably approaches the optimal experimental precision that one can obtain with power-compensated DSC methods (at least up to roughly $500-600 \mathrm{~K}$ ).

We choose the DSC data for synthetic andradite SD23 to fit a $C_{p}$ polynomial for use above room temperature (Berman \& Brown, 1985), because the data set for this sample covers the largest temperature interval and the $C_{p}$ data are well behaved. Applying the method of non-linear least squares yields:

$C_{p}(\mathrm{~J} / \mathrm{mol} \cdot \mathrm{K})=599.09( \pm 14)-2709.5( \pm 480) \cdot T^{-0.5}$ $-1.3866( \pm 0.26) \cdot 10^{7} \cdot T^{-2}+1.6052( \pm 0.42) \cdot 10^{9} \cdot T^{-3}(4)$.

This polynomial describes all the $C_{p}$ data within $\pm 0.5 \%$ and can be used safely up to about $1000 \mathrm{~K}$. 
Table 4. $C_{p}(298 \mathrm{~K})$ and $S^{\circ}$ values of andradite for synthetic and natural samples and description.

\begin{tabular}{|c|c|c|c|}
\hline Sample & $\begin{array}{l}C_{p}(\mathrm{PPMS} / \mathrm{DSC} \text { at } \\
298.15 \mathrm{~K})(\mathrm{J} / \mathrm{mol} \cdot \mathrm{K})\end{array}$ & $\begin{array}{l}S^{\circ}(0 \text { to } 298.15 \mathrm{~K}) \\
(\mathrm{J} / \mathrm{mol} \cdot \mathrm{K})\end{array}$ & Comments \\
\hline Robie et al. (1987) & 351.9 & $316.4 \pm 2.0$ & $\begin{array}{l}\text { Synthetic sample, adiabatic calorimetry with } 34.507 \mathrm{~g} \\
\text { material with } \sim 2 \% \text { wollastonite. }\end{array}$ \\
\hline Robie et al. (recalculation \#1) & - & 330.8 & Calculated using corrected $S_{\mathrm{mag}}$ value (see text). \\
\hline Robie et al. (recalculation \#2) & - & $\sim 330$ & $\begin{array}{l}\text { Corrected for } 6.7 \mathrm{~mol} \% \text { wollastonite in andradite sample } \\
\text { and starting with } S^{\circ}=330.8 \mathrm{~J} / \mathrm{mol} \cdot \mathrm{K} \text { (see text). }\end{array}$ \\
\hline 4282 & $343.9 / 345.3$ & $321.8 \pm 2.2$ & Natural single crystal \\
\hline VM-11 & $344.9 / 345.0$ & $321.9 \pm 2.2$ & Natural single crystal \\
\hline $113-102$ & $342.8 / 346.4$ & $324.5 \pm 2.3$ & Natural single crystal \\
\hline Bal-1 & $348.7 / 348.3$ & $325.7 \pm 2.3$ & Natural single crystal \\
\hline SD23 & $347.0 / 347.2$ & $325.0 \pm 2.3$ & Polycrystalline synthetic \\
\hline And \#27 & $338.1 / 341.3$ & - & $\begin{array}{l}\text { Polycrystalline synthetic, small amount Pt metal } \\
\text { contamination }\end{array}$ \\
\hline
\end{tabular}

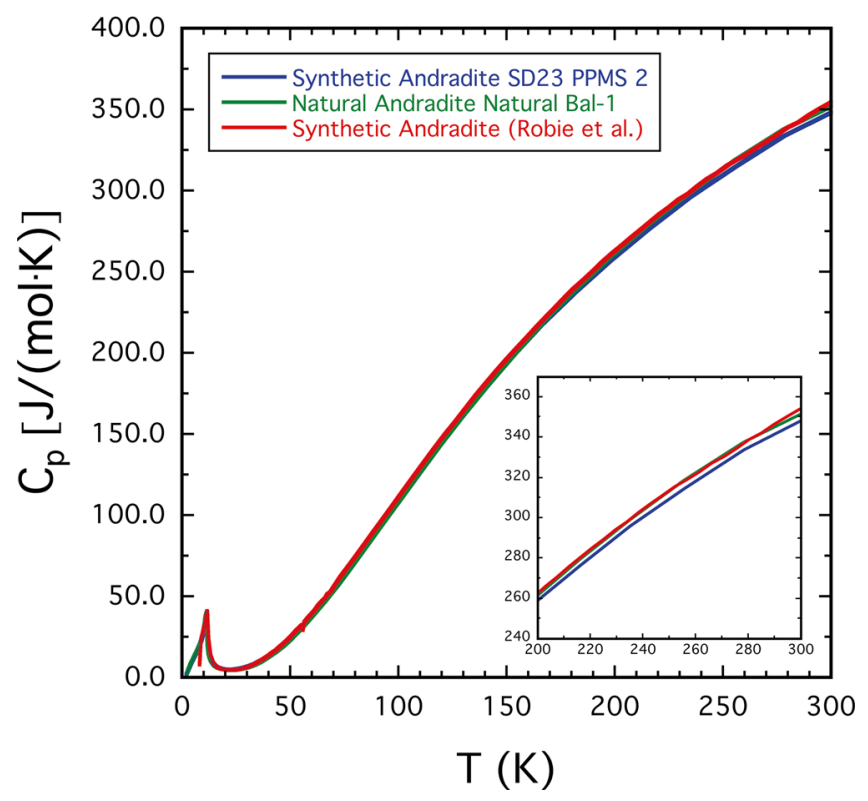

Fig. 3. Interpolated and smoothed $C_{p}$ behavior for andradite samples studied by relaxation calorimetry between 2 and $300 \mathrm{~K}$. The smoothed adiabatic calorimetry $C_{p}$ results of Robie et al. (1987) are also shown and they are very slightly higher in value compared to the samples investigated in this work. The natural andradite crystal Bal-1 also shows slightly larger $C_{p}$ values compared to the other garnets measured in this study. A low-temperature magnetic phase transition is shown with a Néel temperature of about $11 \mathrm{~K}$ (see text and Figs. 6 and 7). The insert shows $C_{p}$ behavior between $200 \mathrm{~K}$ and $300 \mathrm{~K}$.

\section{Discussion}

\section{1. $C_{p}$ behavior of andradite below $300 \mathrm{~K}$ : synthetic vs. natural garnets and a comparison of adiabatic, relaxation and DSC results}

Although the important subject matter of possible differences in thermodynamic behavior between synthetic vs. natural minerals has been broached in the past (e.g., Helgeson et al., 1978; Westrum, 1978), surprisingly little quantitative research has been done in this direction.

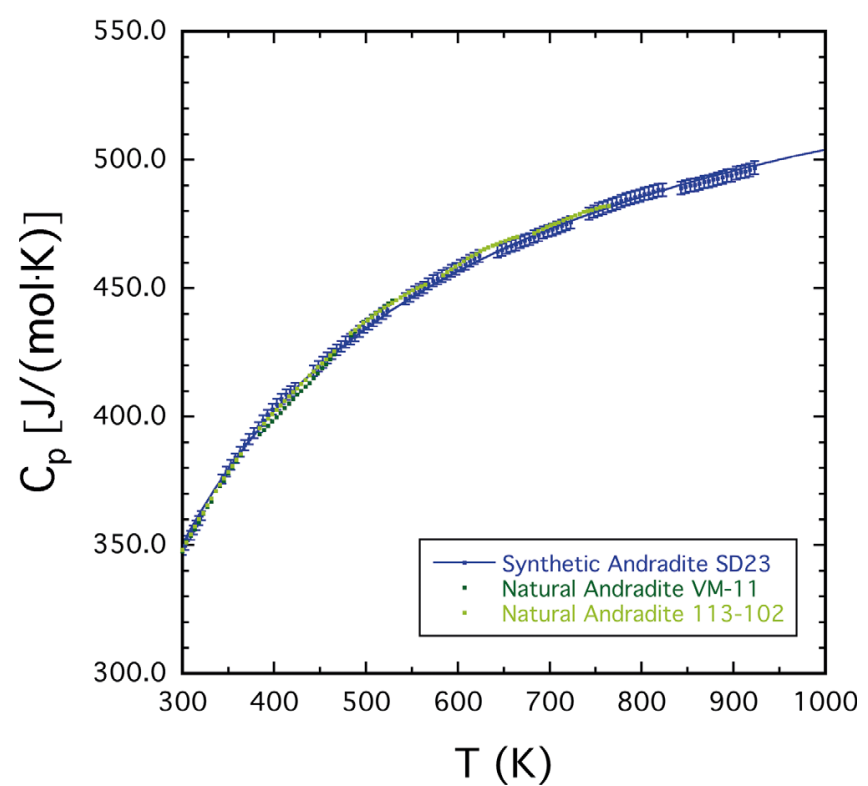

Fig. 4. Comparison of DSC $C_{p}$ results for synthetic SD23 (error bars $\pm 0.5 \%$ ) and the two natural crystals $113-102$ and VM-11. The three data sets agree within $\pm 0.5 \%$ uncertainty. The line represents the best fit $C_{p}$ polynomial given by eqn. (4) in the text.

Probably the most extensive investigation in this regard is in terms of calorimetry centered on the garnet grossular $\mathrm{Ca}_{3} \mathrm{Al}_{2} \mathrm{Si}_{3} \mathrm{O}_{12}$ (see discussion in Dachs et al., 2012a). Here, the $C_{p}$ results on a number of samples and from different investigations are extensive. It was shown that synthetic grossular and natural nearly end-member crystals have small but measurable and meaningful differences in $C_{p}(T)$ behavior, giving rise to $S^{\circ}$ values from $\sim 260 v s . \sim 254 \mathrm{~J} / \mathrm{mol} \cdot \mathrm{K}$, respectively. The $C_{p}$ of natural crystals shows smaller values at temperatures roughly between 10 and $100 \mathrm{~K}$.

Andradite has similarities to grossular in terms of both its mode of occurrence and crystal chemistry. Both can occur from lower- to higher-grade metamorphic rocks, usually in solid solution with one another. Grossular and andradite are also commonly marked by complex 
anisotropic optical behavior (Fig. S2), but the precise origin for it is not fully understood (e.g., Hirai et al., 1982). A single-crystal structure refinement on an anisotropic natural andradite yielded triclinic space group symmetry, I-1 (Kingma \& Downs, 1989) and grossular can show symmetries lower than cubic (see references in Dachs et al., 2012a). This may indicate possible partial long-range cation ordering. On the other hand, in terms of andradite, Adamo et al. (2011) refined several natural single crystals (including one from Val Malenco, Italy) in cubic symmetry $I a-3 d$ and optically anisotropic andradites have been refined in space group $I a-3 d$ using high-resolution synchrotron radiation (Antao et al., 2015). The cubic space group does not allow for long-range atomic ordering. Unlike the case for grossular, based on the extensive results of this study, we do not observe any distinctly measurable differences in the $C_{p}$ and $S^{\circ}$ behavior between isotropic (113-102) and anisotropic (VM-11, 4282, and Bal-1) andradite crystals.

Robie et al. (1987) studied the $C_{p}$ of a single, synthetic andradite sample using adiabatic calorimetry and an earlygeneration power-compensated DSC device. We can compare their results with those from our relaxation calorimeter and later-generation DSC made down to roughly $150 \mathrm{~K}$. Consider first $C_{p}$ behavior below $300 \mathrm{~K}$. Fig. 5 shows the raw adiabatic $C_{p}$ data from Robie et al. and our results obtained on andradite SD23. The agreement between the lower temperature $(<300 \mathrm{~K})$ DSC and relaxation data is excellent. On the other hand, the adiabatic $C_{p}$ data beginning at about $150 \mathrm{~K}$ and with increasing temperature lie at slightly higher values. For example, Robie et al. (1987) report a $C_{p}(298.15 \mathrm{~K})$ value of $351.9 \mathrm{~J} / \mathrm{mol} \cdot \mathrm{K}$, while the various samples from this study show $C_{p}(298.15 \mathrm{~K})$ from about 345 to $348 \mathrm{~J} / \mathrm{mol} \cdot \mathrm{K}$. It is to be noted that the synthetic andradite of Robie et al. (1987) contained about $2 \%$ wollastonite, which they considered to be related to the synthesis route adopted. They stated that they corrected their $C_{p}$ results for the presence of wollastonite. However, their Table 3 of smoothed thermodynamic properties, including $C_{p}$, show similar values as their raw experimental $C_{p}$ data. The reason for this is not clear to us.

Based on our more extensive results on both wellcharacterized natural and synthetic samples, we argue that the $C_{p}$ data, herein, describe better the thermophysical behavior of andradite at low temperatures. Robie et al. (1987) present a $S^{\circ}$ value of $316.4 \mathrm{~J} / \mathrm{mol} \cdot \mathrm{K}$, lower by about $3 \%$ compared to our recommended value of $S^{\circ} \approx 324 \mathrm{~J} / \mathrm{mol} \cdot \mathrm{K}$. On further closer inspection of the data of Robie et al., other issues come to light and, now, we analyze the low-temperature magnetic phase transition in andradite in detail.

\subsection{Magnetic phase transition}

An early X-ray crystal-structure determination of andradite (Menzer, 1928) and later refinements of both natural (Novak \& Gibbs, 1971; Armbruster \& Geiger, 1993;

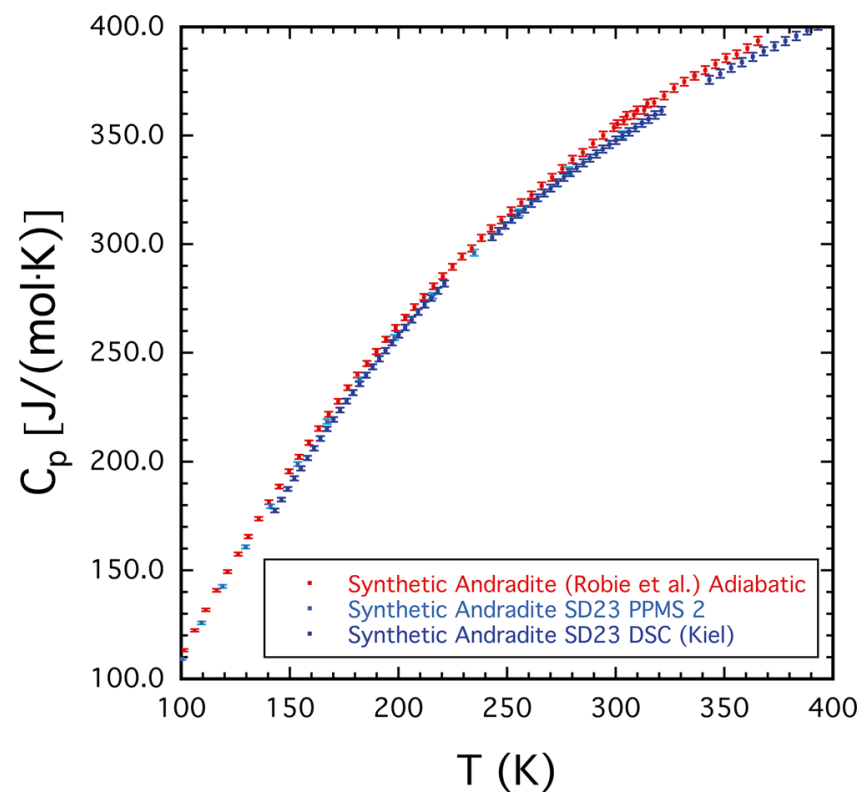

Fig. 5. Comparison of raw low-temperature $C_{p}$ data $(T<400 \mathrm{~K})$ from three different calorimetric set-ups made in three different laboratories. The data points show $\pm 0.5 \%$ error bars. There is excellent agreement in $C_{p}$ behavior for synthetic andradite SD23 measured via relaxation calorimetry (PPMS - Salzburg) and low temperature DSC (Kiel). $C_{p}$ data from the adiabatic calorimetry study of Robie et al. (1987) are slightly higher mostly above roughly $150 \mathrm{~K}$ and with increasing deviation with increasing temperature (for example, $C_{p}$ is greater at $298 \mathrm{~K}$, that is $351.9 \mathrm{~J} / \mathrm{mol} \cdot \mathrm{K} v s . \sim 347 \mathrm{~J} /$ $\mathrm{mol} \cdot \mathrm{K}$ (PPMS and DSC) for sample SD23).

Adamo et al., 2011) and synthetic crystals (Armbruster \& Geiger, 1993) have been made. The structures of both types of crystals are very similar with no marked differences. The Ca cation occurs in eight-fold coordination at the $24 c$ Wyckoff crystallographic site and $\mathrm{Fe}^{3+}$ is six-fold coordinated at the $16 a$ site. The $\mathrm{Fe}^{3+}$ cation is characterized as having one electron in each of the five different $d$ orbitals. Thus, no spin-allowed electronic transitions are permitted, as shown by the UV/VIS spectra (Fig. 2). The electron spins are thermally disordered (i.e., paramagnetic state) at ambient conditions, but they start to order at very low temperatures giving rise to an antiferromagentic transition at $11.5 \pm 0.1 \mathrm{~K}$ (i.e., Néel temperature $-T_{N}$, ), as based on ${ }^{57} \mathrm{Fe}$ Mössbauer spectroscopic measurements (Murad, 1984).

The thermal behavior of this magnetic transition is clearly shown by our closely spaced relaxation-calorimetry measurements made down to $2 \mathrm{~K}$ (Fig. 6 and Appendix 1). The adiabatic calorimetry measurements (Robie et al., 1987), on the other hand, were only made down to $8 \mathrm{~K}$ and with limited data coverage. Of critical importance, here, we note that the two lowest temperature $C_{p}$ data (i.e., at $8.17 \mathrm{~K}$ and $8.40 \mathrm{~K}$ ) were used in the description of the transition. However, we think that our more extensive lowtemperature relaxation measurements down to $2 \mathrm{~K}$ give a better description of the thermal behavior (thus, for example, the $C_{p}$ value at $5 \mathrm{~K}$ in Table 3 (Robie et al., 1978) of smoothed and fitted thermodynamic properties is too low). 


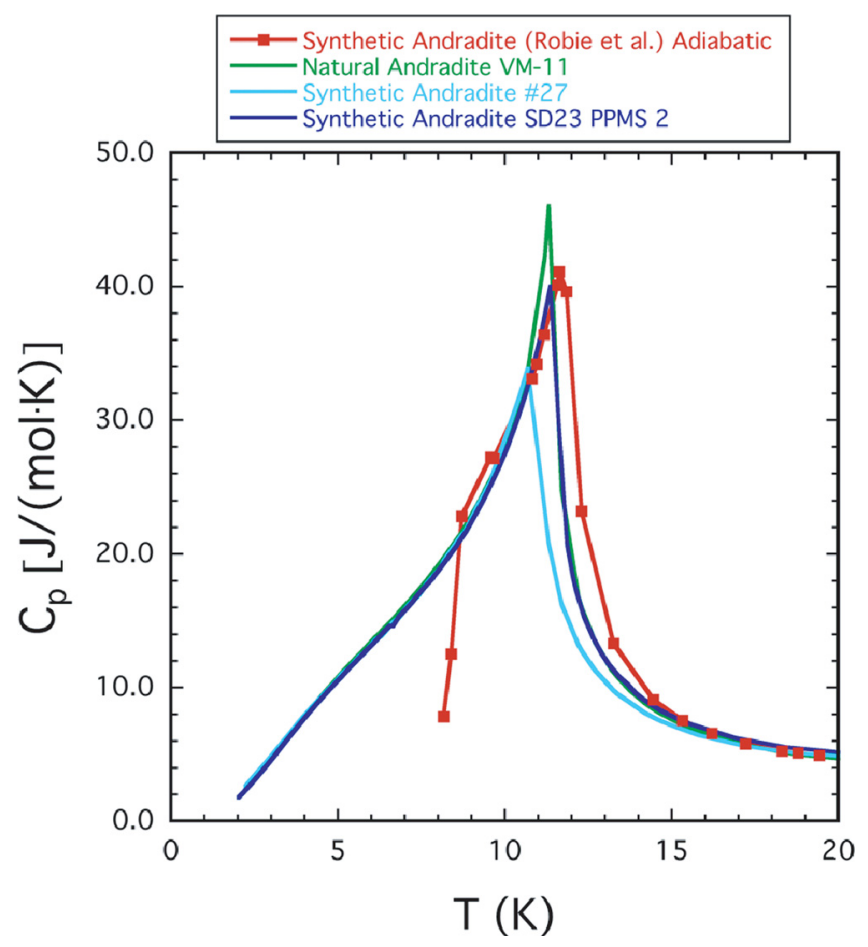

Fig. 6. Comparison of the thermal behavior of the paramagneticantiferromagnetic phase transition for four andradite samples, both synthetic and natural. The $C_{p}$ data points from Robie et al. (1987) are shown as squares, as well as the interpolated $C_{p}$ behavior. Their two lowest-temperature data are probably marked by experimental problems in the adiabatic calorimeter, on the basis of the present results. The natural andradite VM-11 and the synthetic andradite SD23 show $T_{N}=11.3 \pm 0.2 \mathrm{~K}$, while synthetic And \#27 has $T_{N}=10.7 \pm 0.3 \mathrm{~K}$ (see text for discussion).

Figure 7 shows the results of our Komada-Westrumtype modeling to separate and describe $C_{\mathrm{vib}}$ and $C_{\mathrm{mag}}$ behavior in andradite (see also Table 5). The thermal effects of $\mathrm{Fe}^{3+}$ spin ordering begin at about $34 \mathrm{~K}$ and $C_{\mathrm{mag}}$ increases in value with decreasing temperature developing ultimately into a $\lambda$-type anomaly with $T_{N}=11.3 \pm 0.2 \mathrm{~K}$. The modeled $S_{\text {mag }}$ value associated with this transition is $28.1 \mathrm{~J} / \mathrm{mol} \cdot \mathrm{K}$. The theoretical molar magnetic entropy can be calculated by (Gopal, 1966):

$S_{\mathrm{mag}}=R \ln (2 s+1)=29.79 \mathrm{~J} / \mathrm{mol} \cdot \mathrm{K}$

where $R$ is the gas constant and $(2 s+1)$ gives the number of quantized electron spin orientations $(s)$ and thus is in excellent agreement with the model result.

On a further note, our $C_{p}$ results show that $T_{N}$ for sample And \#27 is very slightly lower in value than the other andradites (Fig. 6). This synthetic garnet shows $T_{N}=10.7$ $\pm 0.3 \mathrm{~K}$, whereas $T_{N}$ for all other andradite samples is $11.3 \pm 0.2 \mathrm{~K}$. The latter value is in excellent agreement with the Mössbauer results. The precise physical explanation for the slightly lower $T_{N}$ value for And \#27 is not clear, but it is noteworthy that it also shows a different UV/VIS spectrum compared to natural nearly end-member composition andradite crystals. It is quite possible that this synthetic crystal has a slightly different

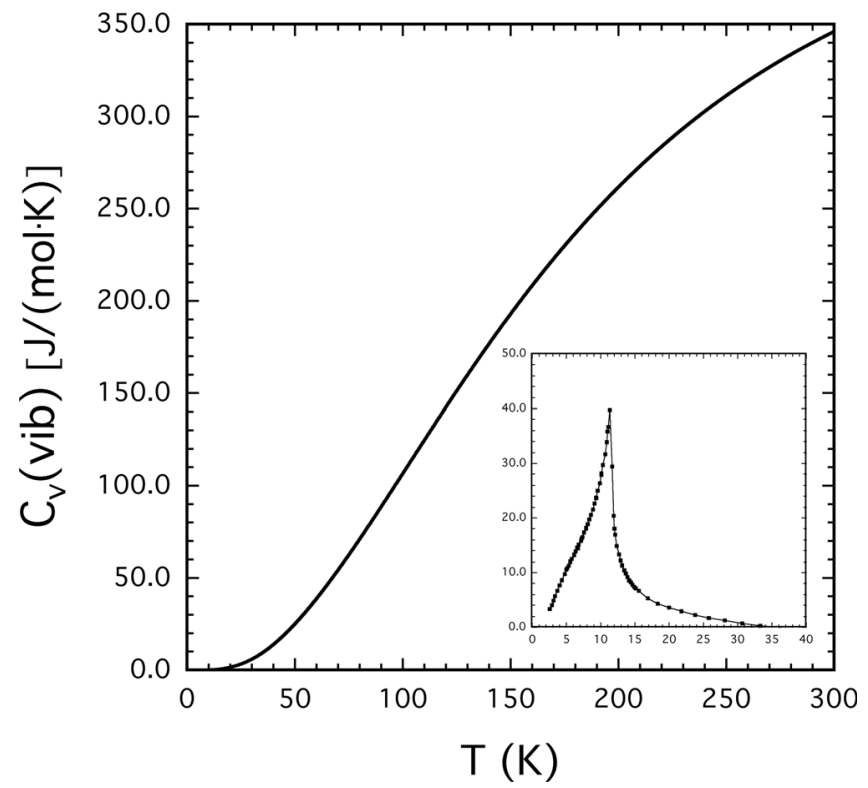

Fig. 7. Model $C_{v}$ (vib) behavior of andradite between 0 and $300 \mathrm{~K}$ (see text for an explanation of the modeling) using $C_{p}$ results from sample SD23. The inset shows $C_{\text {mag }}$ behavior between 2 and $34 \mathrm{~K}$ for the antiferromagnetic phase transition with $T_{N}=11.3 \mathrm{~K} \pm 0.2 \mathrm{~K}$.

Table 5. Model magnetic and vibrational entropy values for andradite SD23 and their sum giving $S^{\circ}$.

\begin{tabular}{|c|c|c|c|}
\hline Sample & $S_{\mathrm{mag}}(\mathrm{J} / \mathrm{mol} \cdot \mathrm{K})$ & $S_{\text {vib }}(298 \mathrm{~K})(\mathrm{J} / \mathrm{mol} \cdot \mathrm{K})$ & $S^{\circ}(\mathrm{J} / \mathrm{mol} \cdot \mathrm{K})$ \\
\hline SD23 & 28.1 (29.79 theory) & 296.9 & 325.0 \\
\hline
\end{tabular}

crystal-chemical and/or electronic state than the natural garnets. It may contain, for example, very minor $\mathrm{Fe}^{2+}$ at the $24 c$ and/or $16 a$ sites that are below the detection limits of ${ }^{57} \mathrm{Fe}$ Mössbauer spectroscopy, which do not show measurable $\mathrm{Fe}^{2+}$ (Armbruster \& Geiger, 1993).

In our previous $C_{p}$ investigation on the garnet almandine, $\mathrm{Fe}_{3} \mathrm{Al}_{2} \mathrm{Si}_{3} \mathrm{O}_{12}$, we observed slight differences in $T_{N}$ and thermal peak behavior relating to a lowtemperature magnetic transition at $9.2 \mathrm{~K}$ (Dachs et al., $2012 \mathrm{~b}$ ). The transition is again caused by an ordering of electron spins but in this case of $\mathrm{Fe}^{2+}$ at the $24 c$ site. The exact $T_{N}$ appears to be affected by small amounts of $\mathrm{Fe}^{3+}$ present at the $16 a$ site. It follows that magnetic phase transition behavior in garnet appears to be sensitive to the precise electronic state. This aspect has not been studied, as best we know, for other common silicates and more work is required.

\subsection{Standard third-law entropy, $S^{\circ}$, of andradite}

\subsubsection{Calorimetry}

Robie et al. (1987) presented a calorimetrically-based standard entropy value for andradite of $316.4 \pm 2.0 \mathrm{~J} /$ $\mathrm{mol} \cdot \mathrm{K}$. This is lower than our best estimate value of $S^{\circ} \approx 324 \pm 2 \mathrm{~J} / \mathrm{mol} \cdot \mathrm{K}$ that is based on results from both 
natural and synthetic samples. There are several issues concerning the Robie et al. investigation that require careful analysis. These authors state "Because of the large heat capacity at the lowest temperature at which measurements were made and because of the much reduced precision in the measurements below $10 \mathrm{~K}$, the uncertainty in the extrapolation of $C_{p, m}^{\circ}$ to $0 \mathrm{~K}$ introduces a quite sizeable uncertainty in $S_{m}^{\circ}(298.15 \mathrm{~K})$." Indeed, it is clear that the manner in which the phase transition is treated (see discussion above and Robie et al., 1987 Fig. 1) will affect $S^{\circ}$. We calculated $S^{\circ}$ using the Robie et al. (1987) $C_{p}$ data set and by extrapolating the low temperature flank of the magnetic transition towards $0 \mathrm{~K}$ using our $C_{p}$ results below $8 \mathrm{~K}$. Doing this, we obtain $S^{\circ}=330.8 \mathrm{~J} / \mathrm{mol} \cdot \mathrm{K}$ (Table 4), which is larger than their reported value. A further issue regards the presence of about 2 vol.\% wollastonite in their synthetic sample and how it was treated in their data analysis. It is not fully clear how they calculated $C_{p}(T)$ and $S^{\circ}$ in their study. We calculate a "wollastonite-corrected" $S^{\circ}$ from their $C_{p}$ data, using our revised value of $330.8 \mathrm{~J} / \mathrm{mol} \cdot \mathrm{K}$, under the assumption of 2 vol.\% wollastonite in the sample (see Robie et al., 1987). Converting vol. $\%$ to mol $\%$, we obtain $6.7 \mathrm{~mol} \%$ wollastonite and $93.3 \mathrm{~mol} \%$ andradite, and taking a value of $S^{\circ}=163.4 \mathrm{~J} / \mathrm{mol} \cdot \mathrm{K}$ for wollastonite (Robie \& Hemingway, 1995), we obtain a final corrected $S^{\circ}$ value of $\sim 330 \mathrm{~J} / \mathrm{mol} \cdot \mathrm{K}$ (Table 4). The $S(T)$ behavior for andradite from $0 \mathrm{~K}$ to $298 \mathrm{~K}$ is given in Geiger \& Dachs (2018). It shows that $S(T)$ is underestimated by the Robie et al. (1987) results at about $T<13 \mathrm{~K}$ and slightly overestimated at roughly $T>50 \mathrm{~K}$. Finally, in another early calorimetric investigation, Kiseleva et al. (1972) reported $S^{\circ}$ value of $329.28 \pm 5.4 \mathrm{~J} / \mathrm{mol} \cdot \mathrm{K}$ (Table 4).

\subsubsection{Vibrational spectroscopy and model heat- capacity behavior}

The $C_{\text {vib }}$ and $S_{\text {vib }}$ behavior of a crystal can be calculated from knowledge of its phonon density of states (DOS). A complete phonon DOS determination, as would be given by neutron diffraction measurements and lattice dynamic calculations, is not at hand for andradite. To circumvent such laborious study, Kieffer (1979a,b) proposed a simplified lattice-dynamic model, using Raman and IR spectra, along with the input of other physical data, to obtain the DOS and ultimately $C_{p \text {,vib }}$ and $S_{\text {vib }}$ of a crystal. Kieffer (1980) thereby calculated a value for $S^{\circ}$ of $322.67 \mathrm{~J} / \mathrm{mol} \cdot \mathrm{K}$ for andradite. This is in remarkably good agreement with the value proposed here of $S^{\circ} \approx 324 \mathrm{~J} / \mathrm{mol} \cdot \mathrm{K}$. Later, Madon et al. (1991), adopting the Kieffer model, suggested a value of $S^{\circ} \approx 313.6 \mathrm{~J} / \mathrm{mol} \cdot \mathrm{K}$ apparently in their attempt to bring it in line with Robie et al.'s (1987) value of $S^{\circ}=316.4 \mathrm{~J} / \mathrm{mol} \cdot \mathrm{K}$. This was achieved by adopting a reduced theoretical value for $S_{\text {mag }}$ of $17.3 \mathrm{~J} / \mathrm{mol} \cdot \mathrm{K}$, for which there are no physical grounds (see discussion above). Indeed, Madon et al.'s model calculations give $S_{\mathrm{v}}^{\circ}=324.7 \mathrm{~J} / \mathrm{mol} \cdot \mathrm{K}$ and $S_{\mathrm{v}(\text { anhar. })}^{\circ}=326.1$ $\mathrm{J} / \mathrm{mol} \cdot \mathrm{K}$ (constant volume and with an anharmonic correction, respectively - see Madon et al., 1991), when the full theoretical $S_{\text {mag }}$ value of $29.8 \mathrm{~J} / \mathrm{mol} \cdot \mathrm{K}$ is used.

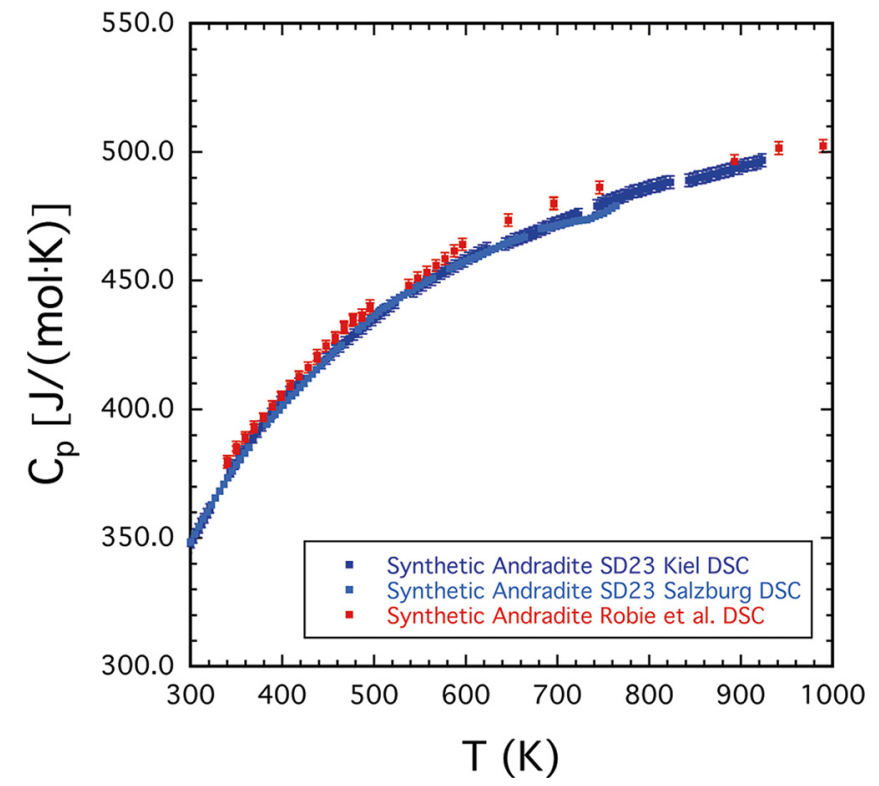

Fig. 8. Comparison of DSC $C_{p}$ results of synthetic SD23 andradite measured in this study and those of Robie et al. (1987). The results for SD23 (dark blue Kiel and light blue Salzburg) and the synthetic sample of Robie et al. (1987) are shown with $\pm 0.5 \%$ error bars. Some $C_{p}$ data from the Robie et al. investigation are slightly higher, especially between roughly 600 and $800 \mathrm{~K}$ compared to all natural and synthetic andradites measured in Kiel and Salzburg (see text).

The good agreement between model $C_{p}$ and $S^{\circ}$ behavior, based on simple IR and Raman spectroscopic results and experimental calorimetry, is remarkable. We note, however, that in the case of other transition-metal-bearing garnets, such as almandine and spessartine, there appears to be differences between model calorimetric-based and theoretical $S_{\text {mag }}$ values (Dachs et al., 2009, 2012b). The reason for this is not understood.

\subsubsection{Thermodynamic behavior from phase equilibrium results and in databases}

It is also necessary to consider $S^{\circ}$ values obtained from phase-equilibrium results and those found in various thermodynamic databases (Table 6). An early calculation of $S^{\circ}$ (Taylor \& Liou, 1978) from phase-equilibrium data is clearly too low in value, as is the value in the early thermodynamic database of Helgeson et al. (1978). Improved thermodynamic properties for many rockforming silicates are given in internally consistent thermodynamic databases (e.g., Gottschalk, 1997; Chatterjee et al., 1998; Holland \& Powell, 2011). All their $S^{\circ}$ values are similar to the $S^{\circ}$ value of Robie et al. (1987).

\subsection{High-temperature $C_{p}$ behavior above $300 \mathrm{~K}$ : comparison of DSC results}

The DSC is a standard method to measure $C_{p}$ from about 300 to $1000 \mathrm{~K}$. There has been much discussion in the literature concerning the exact accuracy and precision of the method over the years. We discuss, here, the various DSC results on andradite, as there are now results from three different 
Table 6. Various published standard third-law entropy, $S^{\circ}$, values for andradite.

\begin{tabular}{ll}
\hline Type of study and authors & $S^{\circ}(\mathrm{J} / \mathrm{mol} \cdot \mathrm{K})$ \\
\hline Calorimetry & \\
Robie et al. $(1987)$ & $316.4 \pm 2.0$ \\
Kiseleva et al. $(1972)$ & $329.28 \pm 5.4$ \\
Phase equilibrium & $285.35 \pm 12.55$ \\
Taylor \& Liou (1978) & \\
Thermodynamic data base & 293.42 \\
Helgeson et al. (1978) & $317.424(0.304)$ \\
Gottschalk (1997) & $315.887(1.706)$ \\
Chatterjee et al. $(1998)$ & 318.4 \\
Berman (2007) & 316.40 \\
Holland \& Powell (2011) & \\
Vibrational spectroscopy and modeling & $322.67[$ model lattice entropy $(292.9)+$ theoretical magnetic entropy $(29.8)]$. \\
Kieffer (1980) & $\approx 313.6\left[\right.$ model lattice entropy $\left(S_{v}=294.9\right)$ or $\left(S_{v(\text { anhar. }}=296.3\right)+$ "reduced" magnetic \\
Madon et al. (1991) & entropy (17.3)]. \\
&
\end{tabular}

laboratories (USGS, Kiel, Salzburg), which is an uncommon situation for minerals (Fig. 8). We note that there is excellent agreement in the $C_{p}$ data sets obtained in the Kiel and Salzburg DSC laboratories using the same andradite sample SD23 and with more recently built DSC devices. On the other hand, the older $C_{p}$ data from Robie et al. (1987) appear slightly too high especially between 600 and $800 \mathrm{~K}$. We conclude, based on numerous $C_{p}$ measurements on various minerals in two different DSC laboratories (Kiel and Salzburg) over the years, that it may be possible to achieve an experimental precision in the best cases of roughly $\pm 0.5 \%$. Precision and accuracy are a function of temperature and they decrease with increasing temperature. This is an improvement over older DSC measurements, as Robie et al. (1987) state that their DSC results have a precision of $1.0 \%$. We think uncertainties for the older measurements can be even higher (see Bosenick et al., 1996).

Acknowledgments: R. Boccio (University of Mailand, Italy, sample VM-11) and C. Ferraris (Muséum National d'Histoire Naturelle, Paris, France, sample 113-102) generously donated crystals for study. S. Speziale (Potsdam) kindly made the photos under crossed polars. This research was supported by grants to C.A.G. from the Austrian Science Fund (FWF: P 25597-N20; FWF and P 30977-NBL). D. Belmonte and two anonymous reviewers made constructive and thorough comments that improved the manuscript.

\section{References}

Adamo, I., Bocchio, R., Diella, V., Pavese, A., Vignola, P., Prosperi, L. Palamza, V. (2009): Demantoid from Val Malenco, Italy: Review and Update. Gems Gemol., 45, 280-287.

Adamo, I., Gatta, G.D., Rotiroti, N., Diella, V., Pavese, A. (2011): Green andradite stones: gemmological and mineralogical characterisation. Eur. J. Mineral., 23, 91-100.
Adamo, I., Bocchio, R., Diella, V., Caucia, F., Schmetzer, K. (2015): Demantoid from Balochistan, Pakistan: gemmological and mineralogical characterization. J. Gem., 34, 428-433.

Amthauer, G. \& Rossman, G.R. (1998): The hydrous component in andradite garnet. Am. Mineral., 83, 835-840.

Antao, S.M., Zaman, M., Gonitjo, V.L., Camargo, E.S., Marr, R.A. (2015): Optical anisotropy, zoning, and coexistence of two cubic phases in andradites from Quebec and New York. Contrib. Mineral. Petrol., 169, 2-17.

Armbruster, T. \& Geiger, C.A. (1993): Andradite crystal chemistry, dynamic X-site disorder and structural strain in silicate garnets. Eur. J. Mineral., 5, 59-71.

Benisek, A. \& Dachs, E. (2008): The uncertainty in determining the third law entropy by the heat-pulse calorimetric technique. Cryogen., 48, 527-529.

Benisek, A., Dachs E., Kroll, H. (2010): Excess heat capacity and entropy of mixing in ternary series of high structural state feldspars. Eur. J. Mineral., 22, 403-410.

Berman, R.G. (2007): winTWQ (version 2.3): A software package for performing internally-consistent thermobarometric calculations. Geol. Surv. Can., Open File 5462. 1-41.

Berman, R. G. \& Brown, T. H. (1985): Heat capacity of minerals in the system $\mathrm{Na}_{2} \mathrm{O}-\mathrm{K}_{2} \mathrm{O}-\mathrm{CaO}-\mathrm{MgO}-\mathrm{FeO}-\mathrm{Fe}_{2} \mathrm{O}_{3}-\mathrm{Al}_{2} \mathrm{O}_{3}$ $\mathrm{SiO}_{2}-\mathrm{TiO}_{2}-\mathrm{H}_{2} \mathrm{O}-\mathrm{CO}_{2}$ : representation, estimation, and high temperature extrapolation. Contrib. Mineral. Petrol., 89, $168-183$.

Bocchio, R., Adamo, I., Diella, V. (2010): The profile of trace elements, including the REE, in gem-quality green andradite from classic localities. Can. Mineral., 48, 1205-1216.

Bosenick, A., Geiger, C.A., Cemic, L. (1996): Heat capacity measurements of synthetic pyrope-grossular garnets between 320 and $1000 \mathrm{~K}$ by differential scanning calorimetry. Geochim. Cosmochim. Acta, 60, 3215-3227.

Burns, R.G. (1993): Mineralogical Applications of Crystal Field Theory. Cambridge University Press, Cambridge, U.K., 551 p.

Chatterjee, N.D., Krüger, R., Haller, G., Olbricht, W. (1998): The Bayesian approach to an internally consistent thermodynamic database: theory, database, and generation of phase diagrams. Contrib. Mineral. Petrol., 133, 149-168. 
Chopelas, A. (2006): Modeling the thermodynamic parameters of six endmember garnets at ambient and high pressures from vibrational data. Phys. Chem. Minerals, 33, 363-376.

Coombs, D.S., Kawachi, Y., Houghton, B.F., Hyden, G., Pringle, I.J., Williams, J.G. (1977): Andradite and andradite-grossular solid solutions in very low-grade regionally metamorphosed rocks in Southern New Zealand. Contrib. Mineral. Petrol., 63, 229-246.

Dachs, E. \& Benisek, A. (2011): A sample-saving method for heat capacity measurements on powders using relaxation calorimetry. Cryogen., 51, 460-464.

Dachs, E. \& Bertoldi, C. (2005): Precision and accuracy of the heatpulse calorimetric technique: low-temperature heat capacities of milligram-sized synthetic mineral samples. Eur. J. Mineral., 17, 251-261.

Dachs, E., Geiger, C.A., von Seckendorff, V., Grodzicki, M. (2007): A low-temperature calorimetric study of synthetic (forsteritefayalite) $\left\{\left(\mathrm{Mg}_{2} \mathrm{SiO}_{4}-\mathrm{Fe}_{2} \mathrm{SiO}_{4}\right)\right\}$ solid solutions: An analysis of vibrational, magnetic and electronic contributions to the molar heat capacity and entropy of mixing. J. Chem. Thermodyn., 39, 906-933.

Dachs, E., Geiger, C.A., Withers, A.C., Essene, E.J. (2009): A calorimetric investigation of spessartine: vibrational and magnetic heat capacity. Geochim. Cosmochim. Acta, 73, 3393-3409.

Dachs, E., Geiger, C.A., Benisek, A., Grevel, K-D. (2012a): Grossular: A crystal chemical, calorimetric, and thermodynamic study. Am. Mineral., 97, 1299-1313.

Dachs, E., Geiger, C.A., Benisek, A. (2012b): Almandine: Lattice and non-lattice heat capacity behavior and standard thermodynamic properties. Am. Mineral., 97, 1771-1782.

Ditmars, D.A., Ishihara, S., Chang, S.S., Bernstein, G., West, E.D. (1982): Measurements of the relative enthalpy of pure $\alpha-\mathrm{Al}_{2} \mathrm{O}_{3}$ (NBS heat capacity and enthalpy standard reference material no. 720) from 10 to 1950 K. J. Res. Nat. Bur. Standards, 87, 5-9.

Fournelle, J. \& Geiger, C.A. (2010): An electron microprobe study of synthetic aluminosilicate garnets. Fall AGU Meeting. V51C2208.

Geiger, C.A. \& Dachs, E. (2018): Recent developments and the future of Low- $T$ calorimetric investigations in the Earth Sciences: consequences for thermodynamic calculations and databases. J. Metamorphic Geol. 36, 283-295.

Geiger, C.A. \& Rossman, G.R. (2018): IR spectroscopy and $\mathrm{OH}^{-}$in silicate garnet: The long quest to document the hydrogarnet substitution. Am. Mineral. 103, 384-393.

Geiger, C.A., Dachs, E., Benisek, A. (2012): Thermodynamic behavior and properties of katoite (hydrogrossular): A calorimetric study. Am. Mineral., 97, 1252-1255.

Gopal, E.S.R. (1966): Specific heats at low temperatures. Plenum Press, New York, 240 p.

Gottschalk, M. (1997): Internally consistent thermodynamic data for rock-forming minerals in the system $\mathrm{SiO}_{2}-\mathrm{TiO}_{2}-\mathrm{Al}_{2} \mathrm{O}_{3}-\mathrm{Fe}_{2} \mathrm{O}_{3}-$ $\mathrm{CaO}-\mathrm{MgO}-\mathrm{FeO}-\mathrm{K}_{2} \mathrm{O}-\mathrm{Na}_{2} \mathrm{O}-\mathrm{H}_{2} \mathrm{O}-\mathrm{CO}_{2}$. Eur. J. Mineral., 9, 175223.

Grimvall, G. (2001): Dependence of thermodynamic properties on atomic masses and bonding in solids. in "Solid Solutions in Silicate and Oxide Systems", C.A. Geiger, ed., EMU Notes in Mineralogy, 3, Eötvös University Press, Budapest, 11-36.

Gustafson, W.I. (1973): The stability of andradite, hedenbergite, and related minerals in the system Ca-Fe-Si-O-H. J. Petrol., 15, 455-496.
Helgeson, H.C., Delany, J.M., Nesbitt, H.W., Bird, D.K. (1978): Summary and critique of the thermodynamic properties of rockforming minerals. Am. J. Sci., 278-A, 1-229.

Hirai, H., Sueno, S., Nakasawa, H. (1982): A lamellar texture with chemical contrast in grandite garnet from Nevada. Am. Mineral., 67, 1242-1247.

Holland, T. J. B. \& Powell R. (1998): An internally consistent thermodynamic dataset for phases of petrological interest. $J$. Metam. Geol., 16, 309-343.

_, - (2011): An improved and extended internally consistent thermodynamic dataset for phases of petrological interest, involving a new equation of state for solids. J. Metam. Geol., 29, 333-383.

Huckenholz, H.G. \& Yoder, H.S., Jr. (1971): Andradite stability relations in the $\mathrm{CaSiO}_{3}-\mathrm{Fe}_{2} \mathrm{O}_{3}$ join up to $30 \mathrm{~Kb}$. N. Jb. Mineral. Abh., 114, 246-280.

Hwang, J.S., Lin, K.J., Tien, C. (1997): Measurement of heat capacity by fitting the whole temperature response of a heatpulse calorimeter. Rev. Sci. Instr., 68, 94-101.

Kieffer, S.W. (1979a): Thermodynamics and lattice vibrations of minerals: 1. Mineral heat capacities and their relationships to simple lattice vibrational models. Rev. Geophys. Space Phys., 17, 1-19.

— (1979b): Thermodynamics and lattice vibrations of minerals: 2 . Vibrational characteristics of silicates. Rev. Geophys. Space Phys., 17, 20-34.

- (1980): Thermodynamics and lattice vibrations of minerals: 4. Application to chain and sheet silicates and orthosilicates. Rev. Geophys. Space Phys., 18, 862-886.

Kingma, K.J. \& Downs, J.W. (1989): Crystal-structure analysis of a birefringent andradite. Am. Mineral., 74, 1307-1316.

Kiseleva, I.A., Topor, N.D., Meĺchakova, L.V. (1972): Experimental determination of heat content and heat capacity of grossularite, andradite and pyrope (in Russian). Geokhimiya, 11, 1372-1379.

Klemme, S., van Miltenburg, J.C., Javorsky, P., Wastin, F. (2005): Thermodynamic properties of uvarovite garnet $\left(\mathrm{Ca}_{3} \mathrm{Cr}_{2} \mathrm{Si}_{3} \mathrm{O}_{12}\right)$. Am. Mineral., 90, 663-666.

Kolesov, B.A. \& Geiger, C.A. (1998): Raman spectra of silicate garnets. Phys. Chem. Minerals, 25, 142-151.

Komada, N. \& Westrum, E.F. (1997): Modeling lattice heat capacity contributions by a single-parametric phonon dispersion approach. J. Chem. Thermodyn., 29, 311-336.

Lashley, J.C., Hundley, M.F., Migliori, A., Sarrao, J.L., Pagliuso, P. G., Darling, T.W., Jaime, M., Cooley, J.C., Hults, W.L., Morales, L., Thoma, D.J., Smith, J.L., Boerio-Goates J., Woodfield, B.F., Stewart, G.R., Fisher, R.A., Phillips, N.E. (2003): Critical examination of heat capacity measurements made on a Quantum Design physical property measurement system. Cryogen., 43, 369-378.

Locock, A.J. (2008): An Excel spreadsheet to recast analyses of garnet into end-member components, and a synopsis of the crystal chemistry of natural silicate garnets. Comp. Geosci., 34, 1769-1780.

Madon, M., Ibarguchi, J.I.G., Via, J., Girardeau, J. (1991): Characterization and thermodynamic properties of andradite, $\mathrm{Ca}_{3} \mathrm{Fe}_{2} \mathrm{Si}_{3} \mathrm{O}_{12}$. Am. Mineral., 76, 1249-1260.

Manning, P.G. (1969): Optical absorption studies of grossular, andradite (var colophonite) and uvarovite. Can. Mineral., 9, $723-730$. 
McAloon, B.P. \& Hofmeister, A.M. (1993): Single-crystal absorption and reflection infrared spectroscopy of birefringent grossular-andradite garnets. Am. Mineral., 78, 957-967.

Menzer, G. (1928): Die Kristallstruktur der Granate. Zeit. Kristall., 69, 300-396.

Meyer, A., Pascale, F., Zicovich-Wilson, C.M., Dovesi, R. (2010): Magnetic interactions and electronic structure of uvarovite and andradite garnets. An ab initio all-electron simulation with the CRYSTAL06 program. Inter. J. Quantum Chem., 110, 338-351.

Murad, E. (1984): Magnetic ordering in andradite. Am. Mineral., 69, $722-724$.

Novak, G.A. \& Gibbs, G.V. (1971): The crystal chemistry of the silicate garnets. Am. Mineral., 56, 791-825.

Parry, S.A., Pawley, A.R., Jones, R.L., Clark, S.M. (2007): An infrared spectroscopic study of the $\mathrm{OH}$ stretching frequencies of talc and 10-A phase to $10 \mathrm{GPa}$. Am. Mineral., 92, 525-531.

Petit, S., Martin, F., Wiewiora, A., de Parseval, P., Decarreau, A. (2004): Crystal-chemistry of talc: A near infrared (NIR) spectroscopic study. Am. Mineral., 89, 319-326.

Pezzotta, F., Adamo, I., Diella, V. (2011): Demantoid and topazolite from Antetezambato, northern Madagascar: Review and new data. Gems Gemol., 47, 2-14.

Phillips, W.R. \& Talantsev, A.S. (1996): Russian demantoid, Czar of the garnet family. Gems Gemol., 32, 100-111.

Post, J.L. \& Borer, L. (2000): High-resolution infrared spectra, physical properties, and micromorphology of serpentines. Appl. Clay Sci., 16, 73-85.

Robie, R.A. \& Hemingway, B.S. (1995): Thermodynamic properties of minerals and related substances at $298.15 \mathrm{~K}$ and 1 bar $\left(10^{5}\right.$ pascals) pressure and at higher temperatures. U.S. Geol. Surv. Bull., 2131, $461+$ IV p.
Robie, R.A., Zhao, B., Hemingway, B.S., Barton, M.S. (1987): Heat capacities and thermodynamic properties of andradite garnet, $\mathrm{Ca}_{3} \mathrm{Fe}_{2} \mathrm{Si}_{3} \mathrm{O}_{12}$, between 10 and $1000 \mathrm{~K}$ and revised values for $\Delta_{\mathrm{f}} G_{\mathrm{m}}^{\circ}(298.15 \mathrm{~K})$ of hedenbergite and wollastonite. Geochim. Cosmochim. Acta, 51, 2219-2224.

Rossman, G.R. (2006): Analytical Methods for Measuring Water in Nominally Anhydrous Minerals. in "Water in Nominally Anhydrous Minerals", H. Keppler \& J.R. Smyth, eds., Reviews in Mineralogy and Geochemistry, Mineralogical Society of America, Washington D.C., 62, 1-28.

Shoji, T. (1977): The stability of andradite in $\mathrm{H}_{2} \mathrm{O}-\mathrm{CO}_{2}$ mixtures. J. Japan. Assoc. Mineral. Petrol. Econ. Geol., 72, 399-411.

Suwa, Y., Tamai, Y., Naka, S. (1976): Stability of synthetic andradite at atmospheric pressure. Am. Mineral., 61, 26-28.

Taran, M.N. \& Langer, K. (2000): Electronic absorption spectra of $\mathrm{Fe}^{3+}$ in andradite and epidote at different temperatures and pressures. Eur. J. Mineral., 12, 7-15.

Taylor, B.E. \& Liou, J.G. (1978): The low-temperature stability of andradite in C-O-H fluids. Am. Mineral., 63, 378-393.

Westrum, E.F., Jr. (1978): Low-temperature calorimetry - quo vadis? J. Therm. Analysis, 14, 5-13.

Wykes, J.L., Newton, R.C., Manning, C.E. (2008): Solubility of andradite, $\mathrm{Ca}_{3} \mathrm{Fe}_{2} \mathrm{Si}_{3} \mathrm{O}_{12}$, in a $10 \mathrm{~mol} \% \mathrm{NaCl}$ solution at $800{ }^{\circ} \mathrm{C}$ and 10 kbar: Implications for the metasomatic origin of grandite garnet in calc-silicate granulites. Am. Mineral., 93, 886-892.

Received 1 June 2017

Modified version received 21 November 2017

Accepted 10 December 2017 